\title{
A Longitudinal Field Study to Evaluate the Diagnostic Properties of a Quantitative Real-Time Polymerase Chain Reaction-Based Assay to Detect Staphylococcus aureus in Milk
}

\author{
E. Studer, ${ }^{*}$ W. Schaeren,† J. Naskova, ${ }^{*}$ H. Pfaeffli,‡ T. Kaufmann, ${ }^{*}$ M. Kirchhofer, ${ }^{*}$ A. Steiner, ${ }^{*}$ \\ and H. U. Graber*1 \\ ${ }^{*}$ Clinic for Ruminants, Department of Clinical Veterinary Medicine, Vetsuisse-Faculty of Berne, Bremgartenstrasse 109a, PO Box 8466, \\ 3001 Berne, Switzerland \\ †Agroscope Liebefeld-Posieux, Swiss Federal Research Station for Animal Production and Dairy Products, Schwarzenburgstrasse 161, \\ 3003 Bern, Switzerland \\ ¥Veterinary Practice Pfaeffli, Neufeldstrasse 20, 3454 Sumiswald, Switzerland
}

\section{ABSTRACT}

Bacteriological culture as a diagnostic tool for chronic infections with Staphylococcus aureus intramammary infection is not completely satisfactory. The cyclical shedding pattern of Staph. aureus with intervals of low excretion is considered to be the main reason. We recently developed a novel assay for Staph. aureus in milk, based on real-time quantitative PCR (QPCR). In a longitudinal study of chronically infected cows we evaluated the diagnostic properties of this test under field conditions. Diagnostic sensitivity of the novel test proved to be very high with a value of $99.4 \%$; diagnostic specificity was $97.1 \%$. In addition, the shedding patterns of Staph. aureus for the sampling period were analyzed. Using $\log _{10}$-transformed QPCR data and plotting them across sampling time revealed a sinusoidal shedding pattern in 6 of 11 naturally infected quarters. Shedding patterns obtained by QPCR and by bacteriological culture were synchronous. In conclusion, the novel test has a very high diagnostic sensitivity and specificity so that quarters chronically infected with Staph. aureus are reliably detected, independent from their actual shedding quantity.

Key words: real-time quantitative polymerase chain reaction, mastitic, Staphylococcus aureus, milk

\section{INTRODUCTION}

Staphylococcus aureus is one of the most important etiological agents of chronic, clinical, and subclinical mastitis in Swiss dairy herds as well as worldwide and is of great economic importance (Seegers et al., 2003; Kirchhofer et al., 2007). So far, in practice, the suspicion

Received June 27, 2007.

Accepted January 1, 2008

${ }^{1}$ Corresponding author: hans.graber@knp.unibe.ch for presence of IMI due to Staph. aureus is based on a combination of the following findings: visible changes of milk, atrophy or indurations of the suspected quarter (Radostits et al., 2000), presence of certain risk factors such as teat lesions or callused teats (Sieber and Farnsworth, 1984; Zadoks et al., 2001), elevation of SCC (Schukken et al., 2003), or positive results for the California Mastitis Test. Confirmation or exclusion is based on bacteriological culture of one or several consecutive milk samples.

Bacteriology as the gold standard, however, is not completely satisfactory because its overall diagnostic sensitivity for IMI by Staph. aureus is only 75\%, ranging from 41 to $100 \%$ in individual cases (Sears et al., 1990). Reasons for this low sensitivity are that 1 ) intervals with high shedding of Staph. aureus are followed by those of low or very low shedding, resulting in amounts of pathogen in milk that are frequently below the detection limit of standard bacteriology; 2) the microbiological detection of Staph. aureus is impeded by the intracellular survival in professional (Zecconi et al., 1997; Godden et al., 2002) and nonprofessional phagocytes (Almeida et al., 1996; Wesson et al., 1998), a situation that contributes to false-negative results.

The sensitivity of detecting IMI by Staph. aureus can be increased to $97 \%$ if repeated quarter samples are taken at a 3-d interval and cultured separately (Buelow et al., 1996). Other methods such as optimizing the time point of sampling (premilking vs. postmilking samples) (Sears et al., 1991), freezing and thawing (Godden et al., 2002), or centrifugation of samples before culture (Zecconi et al., 1997) were reported to improve the sensitivity, but their effects are small and normally too laborious or too expensive for an analysis at the herd level.

A novel assay for Staph. aureus pathogen in milk, based on real-time quantitative PCR (QPCR), was recently developed by Graber et al. (2007). This method has a very high analytical sensitivity that is 507 times 
higher than bacteriology using a $10-\mu \mathrm{L}$ aliquot. The analytical specificity of the QPCR assay is $100 \%$, meaning that the other IMI pathogens are safely excluded from detection. This is also true for Staphylococcus hyicus and Staphylococcus intermedius, 2 staphylococcal species whose differentiation from Staph. aureus by conventional bacteriology is often difficult (National Mastitis Council, 1999). The QPCR assay is further characterized by a short period to obtain a definitive result $(<5 \mathrm{~h})$, by excellent intra- and interassay variability, and by good recovery of Staph. aureus from milk. Because of its favorable analytical properties, the assay was further evaluated for its diagnostic sensitivity and specificity analyzed in a longitudinal study under field conditions.

\section{MATERIALS AND METHODS}

\section{Animals}

Housing and Selection of Animals. Twenty Simmental $\times$ Red Holstein dairy cows (10 cows with Staph. aureus IMI and 10 control cows) were selected for this study. They were housed on 6 different farms in the area of the Bernese prealpine foothills in Switzerland. They were all kept in a tied housing system on rubber mats covered with straw. The milking technique was a pipeline milking machine on 2 farms and bucket milking machines on 4 farms. Postmilking teat dipping was practiced on 2 farms, and dry cow therapy was practiced on 4 farms. There were 2 farms with closed population, whereas 4 farmers bought animals occasionally.

Cows with Staph. aureus IMI. We searched for cows naturally infected with Staph. aureus in one or several quarters. A quarter was defined as Staph. aureus-positive after 3 positive samples were collected on 3 consecutive days (24-h intervals) and processed as described below. In particular, a volume of $100 \mu \mathrm{L}$ of milk was used for plating. Per plate, 3 or more colonies typical of Staph. aureus were considered positive. In case of doubt, the isolates were evaluated by PCR for the Staph. aureus-specific nuc gene, as described by Graber et al. (2007).

The selected cows were in their 2nd to 7th lactations and naturally infected with Staph. aureus in 1 quarter, except for 1 cow that was infected in both front quarters. Coinfections in the same or in additional quarters with minor pathogens such as CNS or Corynebacterium spp. were acceptable. There was no information available about the duration of the existing infection. The IMI of the selected quarters had not been treated with antibiotics during the current lactation, before or during the study.

Control Cows. The selection criteria for the control animals were as follows: cows of the same breed, in their 2nd to 7th lactation, no clinical signs of IMI or other diseases affecting udder health, and no treatment with antibiotics during the current lactation.

Three milk samples were collected at 24-h intervals and bacteriologically analyzed as described for the infected quarters. If all 3 samples were free of Staph. aureus, the quarter was considered a control quarter. Minor (more than 10 to about 100 single colonies per plate) to moderate (many single colonies, but still identifiable) growth of further mastitis pathogens such as CNS or Corynebacterium spp. was tolerated to evaluate the diagnostic specificity of the QPCR assay under stringent conditions. Safe exclusion of CNS and other pathogens is particularly important because the prognosis of chronic mastitis caused by these bacteria is much better than that of Staph. aureus mastitis.

Initially and during the sampling period, the udders and quarters of infected and control cows were clinically examined. We evaluated size, shape, and texture (indurations, nodules) of the udder and quarters and teat size, shape, and possible injuries or bruises. Furthermore, the teat ends were checked for irritations and were evaluated according to the teat ring score suggested by Neijenhuis et al. (2000).

\section{Collection of Milk Samples}

Milk samples were collected during a period of 14 consecutive days, approximately $15 \mathrm{~min}$ before the cows were milked in the evening. If necessary, the udder was cleaned of dirt with individual towels. The first milk, about $20 \mathrm{~mL}$, was macroscopically evaluated for color and the presence of clots and then discarded. Teat ends were thoroughly cleaned using gauze pledgets moistened with $70 \%$ ethanol. Individual quarter milk samples (about $10 \mathrm{~mL}$ ) were collected aseptically in sterile vials for bacteriology and QPCR. A second vial was used to collect milk for evaluation of SCC. Samples were immediately cooled on ice and frozen at $-20^{\circ} \mathrm{C}$ within $1 \mathrm{~h}$.

\section{Bacteriological Analysis of Milk Samples}

After thawing at room temperature, milk samples were warmed in a water bath at $37^{\circ} \mathrm{C}$ for $5 \mathrm{~min}$. One hundred microliters of pure milk and 1:10 serial dilutions in PBS were spread with a glass spatula on Columbia agar containing 5\% sheep blood (BA, bioMérieux, Geneva, Switzerland) and on Baird Parker (BP) agar containing rabbit plasma fibrinogen (Oxoid, Basel, Switzerland). The plates were incubated aerobically at $37^{\circ} \mathrm{C}$ and results were evaluated after 24 and $48 \mathrm{~h}$. Bacteria were identified according to the guidelines of the National Mastitis Council (1999), which include 
morphology, biochemical properties, and detection of hemolysis. On BA plates, colonies were considered typical for Staph. aureus if they were large, grayish-white to yellow, catalase-positive, and showed beta or double hemolysis. On BP plates, large black to gray colonies surrounded by an unambiguous, opaque precipitation halo (i.e., coagulase activity) were accepted as Staph. aureus. After 24 and $48 \mathrm{~h}$, colonies typical of Staph. aureus were counted on $\mathrm{BP}$ and BA plates (agar plate count method, APCM). A result was regarded as positive for a specific pathogen if at least 3 typical colonies per plate could be detected.

\section{Preparation of Bacteria and Bacterial Nucleic Acid Extraction}

Bacterial nucleic acid (NA) was extracted directly from raw milk using the technique described by Graber et al. (2007). In brief, milk was thawed, incubated for 5 min in a water bath at $37^{\circ} \mathrm{C}$, and gently inverted several times to obtain a homogeneous suspension.

Milk $(400 \mu \mathrm{L})$ of each sample was pipetted into a solution containing Triton-X100 (Merck, Berne, Switzerland), Lactobacillus casei, and trypsin (Becton Dickinson AG, Basel, Switzerland), and incubated for $15 \mathrm{~min}$ at $55^{\circ} \mathrm{C}$; n-pentane was added, followed by intensive vortexing and centrifuging of the samples. The pellets were resuspended in distilled water and $\mathrm{NaOH}$. After centrifugation, the cell wall was removed by lysozyme and mutanolysin treatment. After a further centrifugation and resuspension, the samples were treated with proteinase $\mathrm{K}$ and NA was isolated using the High Pure PCR Template Preparation Kit (Roche Diagnostics, Rotkreuz, Switzerland). The eluates $(200 \mu \mathrm{L})$ were checked for NA integrity and quantity by standard agarose electrophoresis together with GelRed stain (Biotium Inc., Hayward, CA). Gel staining was performed according to the manufacturer's instruction. The isolated NA were stored at $-20^{\circ} \mathrm{C}$ until further use.

\section{QPCR}

The QPCR for the Staph. aureus-specific nuc gene was performed as described by Graber et al. (2007) and analyzed with GeneAmp 5700 Sequence Detection System (Applied Biosystems, Foster City, CA). In brief, the QPCR mixture consisted of TaqMan Universal PCR Master Mix (Applied Biosystems), upper and lower primer, the fluorescent probe, and the corresponding NA (1:10 diluted in $\mathrm{H}_{2} \mathrm{O}$ ). The QPCR cycling program was as follows: $50^{\circ} \mathrm{C}$ for $2 \mathrm{~min}, 1$ cycle; $95^{\circ} \mathrm{C}$ for $10 \mathrm{~min}$, 1 cycle; $95^{\circ} \mathrm{C}$ for $15 \mathrm{~s}$ and $60^{\circ} \mathrm{C}$ for $1 \mathrm{~min}, 45$ cycles.

To rule out false-negative results due to inhibition of the nuc gene QPCR assay, a second QPCR with the same NA was run, containing an internal control DNA. For this purpose, we used an amplicon obtained from the $\mathrm{N}$ gene of the canine distemper virus. The internal control DNA was amplified by QPCR as described (Graber et al., 2007), using primers specific for the $\mathrm{N}$ gene of the canine distemper virus and a fluorescent probe.

The QPCR for both genes was done in duplicate. For each QPCR run, a standard was included (in duplicate). Various controls were used to monitor the whole procedure (see Graber et al., 2007). The results of QPCR were expressed as staphylococcal cell equivalents (SCE). A QPCR result was deemed positive if at least 1,429 SCE/ $\mathrm{mL}$ of milk were detected (Graber et al., 2007).

\section{SCC}

To analyze the SCC, the milk samples were thawed at room temperature and prewarmed at $37^{\circ} \mathrm{C}$ for 10 min before analysis. The somatic cells were then counted with a Fossomatic 5000 (Foss, Hillerød, Denmark).

\section{Statistical Analysis}

If not otherwise stated, data were expressed as geometric mean, minimum, and maximum values. Diagnostic sensitivity and specificity were computed in the standard manner (OIE, 2004). Linear least squares regression analysis was performed with the bacteriological results $\left(\log _{10} \mathrm{cfu} / \mathrm{mL}\right)$ forming the dependent, and the QPCR results $\left(\log _{10} \mathrm{SCE} / \mathrm{mL}\right)$ the independent variable. Normal distribution of the residuals was demonstrated by quantile-quantile plot followed by the 1-sample Kolmogorov-Smirnov test using normal distribution as the specified distribution.

Comparison Between QPCR and APCM. To check for synchrony of 2 curves with different scales (QPCR vs. APCM), we chose the following approach: if, for a single quarter, the directions of the 2 curves between 2 adjacent time points pointed to the same direction, a value of 1 was assigned to this interval, otherwise the value was 0 . This was continued over the entire period of measurement so that $14-1$ values were received for each quarter forming 1 cluster (cluster j). In total, 11 clusters were obtained, each containing the values of 13 intervals. With these clusters, a Chi-square statistic was calculated (formula 1). In particular, for each cluster $j$, the theoretically expected frequency $\left(\boldsymbol{f} \boldsymbol{e}_{j}\right)$ of concurrence between QPCR and APCM was subtracted from the actually observed frequency $\left(\boldsymbol{f} \boldsymbol{b}_{\boldsymbol{j}}\right)$. The difference was then squared and divided by the expected frequency. Then, the obtained quotients were summed over all the 11 clusters resulting in the chi-square value 
$\left(\chi^{2}\right)$ which was then used for hypothesis testing. Formula 1 was as follows:

$$
\chi^{2}=\sum_{j=1}^{11} \frac{\left(f b_{j}-f e_{j}\right)^{2}}{f e_{j}}
$$

where $f b_{j}=$ observed frequency of " 1 " for cluster $\mathrm{j}, f e_{j}=$ expected frequency of " 1 " for cluster $\mathrm{j}$, and $f e_{j}=\mathrm{n} \times P=$ $13 \times 0.5$ ( $\mathrm{n}=$ number of all the intervals included at cluster j, $P=$ the expected probability to obtain a " 1 " by chance is 0.5 ), and $\mathrm{df}=10$.

If the observed frequencies in cluster $\mathrm{j}$ were smaller than those expected, the corresponding quotient of formula 1 was multiplied by -1 , because smaller values than the expected ones oppose synchrony. The higher the observed chi-square value, the higher the synchrony of 2 curves.

Shedding Patterns. To assess the shedding patterns of Staph. aureus for single quarters, nontransformed and $\log _{10}$-transformed QPCR data were plotted against sampling time and fitted using the LOWESS (locally weighted regression) algorithm (Cleveland, 1979). Quarters with a cyclic pattern $\left(\log _{10}\right.$ data) were further processed for fitting a sinusoidal model. Because of the random start of sampling and the long cycle duration, quarters that showed an incomplete cycle were also included. As a consequence, modeling was restricted to the positive half phase. For the individual quarters, each value was transformed by subtracting the quarter mean to correct for the different quantities of Staph. aureus shed in milk by the different quarters. Because this kind of transformation can lead to negative values, a value of 2 was added to make all the values positive. In addition, the phases were moved to achieve a common starting point for all the included quarters. The model was then fitted using a nonlinear mixed model approach assuming a sinusoidal dependency over time. The intercept was selected as a fixed effect and height of amplitude and duration of half phase were regarded as random effects. To confirm cyclic shedding of Staph. aureus in milk, parametric 1way ANOVA with repeated measures was performed using the same data. To test the fit of the ANOVA model, the fitted values were plotted against the observed values, and the residuals were checked for normal distribution by quantile-quantile plot.

Computation was performed using the SYSTAT 10 software package (Systat Software Inc., Richmond, CA) or S-PLUS 8 (Insightful Switzerland, Zurich, Switzerland). Significance was defined as values of $P<0.05$.

\section{RESULTS}

\section{Examination of Quarters and Teats}

Of 11 infected quarters, 6 were normal to palpation, whereas 1 had nodules, 2 were indurated, and 2 were indurated and had palpable nodules. One of the latter 2 quarters showed clinical signs of a progressive disease such as progredient enlargement and induration and was treated immediately after milk collection on d 14 . Seven quarters were of the same size and shape as their opposite, 4 were obviously smaller. One of them showed a constant decrease of milk yield that was accompanied by an ongoing hypotrophy.

All the teats of infected quarters were of normal shape. One teat carried a few small, single papillomas. Checking the teat orifices with the teat ring score, 8 teats had no ring, 2 had smooth or slightly rough rings, and 1 had a rough ring.

In 10 quarters free of Staph. aureus, there were 2 teats that had a smooth or slightly rough ring according to the teat ring score and 2 teats with flat teat ends. The other quarters and teats looked normal.

\section{QPCR and APCM}

A total of 154 milk samples from 11 infected quarters and 140 samples from 10 control quarters were collected over 14 consecutive days. The QPCR analysis of milk samples obtained from quarters with Staph. aureus IMI was positive in 153 samples and negative in only 1 sample. Bacteriology of milk from quarters with IMI revealed a positive result for Staph. aureus in $141 \mathrm{sam}-$ ples $(91.6 \%)$, either as single species or in combination with other bacteria (see Table 1) such as Streptococcus spp., CNS, or Corynebacterium spp. Thirteen samples (8.4\%) were Staph. aureus-negative and 2 samples were contaminated.

The sample negative by QPCR was also negative by APCM. No sample proved to be positive for Staph. aureus by APCM and negative by QPCR. In 60\% of the milk samples obtained from control cows, no bacterial growth was observed (see Table 1). In case of bacterial growth, CNS (16.4\%) and Corynebacterium spp. (5.7\%) or their combination (12.9\%) was found most frequently. In 1 sample CNS and Streptococcus spp. and in another sample CNS, Streptococcus spp., and Corynebacterium spp. were observed. Five samples were considered contaminated.

Interestingly, there were 2 control quarters that were positive for Staph. aureus by QPCR: 1 of them was positive in a single sample; the other quarter gave a positive result in 3 samples whereby 2 samples were positive on 2 following days.

Between the $\log _{10}$ QPCR and the $\log _{10}$ APCM values (136 paired values), a linear association was found over the range of measurement $\left(30 \mathrm{cfu} / \mathrm{mL}\right.$ to $2.20 \times 10^{7} \mathrm{cfu} /$ $\mathrm{mL})$ : the coefficient of correlation was $0.847(P<0.001)$, the coefficient of regression was $1.130(P<0.001)$, and the constant was $-2.289(P<0.001)$. 
Table 1. Bacteriological results of milk samples from 154 quarters with Staphylococcus aureus IMI and from 140 control quarters

\begin{tabular}{lrr}
\hline Species & $\begin{array}{c}\text { Samples from } \\
\text { infected cows, n (\%) }\end{array}$ & $\begin{array}{c}\text { Samples from } \\
\text { control cows, } \mathrm{n}(\%)\end{array}$ \\
\hline No bacterial growth & $13(8.4)$ & $84(60)$ \\
Staph. aureus & $95(61.7)$ & $0(0)$ \\
Staph. aureus and Streptococcus spp. & $22(14.3)$ & \\
Staph. aureus and CNS & $6(3.9)$ & \\
Staph. aureus and Corynebacterium spp. & $12(7.8)$ & \\
Staph. aureus, Streptococcus spp., & $4(2.6)$ & $23(16.4)$ \\
and Corynebacterium spp. & & $1(0.7)$ \\
CNS & & $18(12.9)$ \\
CNS and Streptococcus spp. & & $1(0.7)$ \\
CNS and Corynebacterium spp. & & $8(5.7)$ \\
CNS, Streptococcus spp., & $2(1.3)$ & $5(3.6)$ \\
and Corynebacterium spp. & $154(100)$ & $140(100)$ \\
Corynebacterium spp. & & \\
Contamination & & \\
Total & & \\
\hline
\end{tabular}

\section{Diagnostic Sensitivity and Specificity}

Overall diagnostic sensitivity of the QPCR method was $99.4 \%$; at the quarter level it varied from 92.9 to $100 \%$ (see Table 2). Overall diagnostic specificity of QPCR was $97.1 \%$, ranging from 78.6 to $100 \%$. Diagnostic specificity of the QPCR was less than $100 \%$ because of the 2 control quarters that were Staph. aureus-positive in 1 and 3 samples, respectively. Diagnostic sensitivity of APCM of $100 \mu \mathrm{L}$ of milk was $91.6 \%$ overall and 71.4 to $100 \%$ at the quarter level. Diagnostic specificity of APCM was $100 \%$.

Taking into account that most laboratories in routine bacteriological diagnostics use $10 \mu \mathrm{L}$ instead of $100 \mu \mathrm{L}$ of milk as we did, the following calculated results were obtained (Table 2): the diagnostic sensitivity and diagnostic specificity of QPCR and the specificity of APCM remained the same, whereas the overall diagnostic sensitivity of bacteriological culture dropped to $79.9 \%$. At the quarter level, sensitivity ranged from 21.4 to $100 \%$. In the case of the quarter with the lowest sensitivity (21.4\%), a positive result would have been observed only 3 times within $14 \mathrm{~d}$. For this quarter, QPCR was always positive.

\section{Shedding Amount and Patterns}

The amount of bacterial shedding differed between the quarters with IMI. For QPCR, the minimal Staph. aureus count was $0 \mathrm{SCE} / \mathrm{mL}$ ( 1 sample), the maximum was $5.69 \times 10^{7} \mathrm{SCE} / \mathrm{mL}$, and the geometric mean was $2.05 \times 10^{5} \mathrm{SCE} / \mathrm{mL}$. For APCM, the minimal count was $0 \mathrm{cfu} / \mathrm{mL}$, the maximum was $2.20 \times 10^{7} \mathrm{cfu} / \mathrm{mL}$, and the geometric mean was $5,900 \mathrm{cfu} / \mathrm{mL}$.

The longitudinal shedding activity of the quarters with Staph. aureus IMI was interpreted in 2 ways: 1) with the untransformed data set, and 2) with the $\log _{10^{-}}$ transformed data to correct for extreme values. The untransformed data showed a shedding pattern with peaks and depressions in every quarter for QPCR and for APCM. In particular 1 (2 quarters), 2 (3 quarters), 3 (4 quarters), or 4 (2 quarters) major shedding peaks were observed (see Figures 1 and 2 for representative shedding patterns).

After $\log _{10}$ transformation of QPCR data and fitting them with the LOWESS algorithm, 3 bacteriological shedding patterns for Staph. aureus were observed: cyclic (see Figure 4; 6 quarters), log-linearly increasing

Table 2. Diagnostic sensitivity and specificity of real-time quantitative PCR (QPCR) and agar plate count method (APCM) using $100 \mu \mathrm{L}$ or $10 \mu \mathrm{L}$ (calculative value) of milk for plating

\begin{tabular}{|c|c|c|c|c|}
\hline \multirow[b]{2}{*}{ Assay } & \multicolumn{2}{|c|}{ Using $100 \mu \mathrm{L}$ for plating } & \multicolumn{2}{|c|}{ Using $10 \mu \mathrm{L}$ for plating } \\
\hline & Overall & Quarter level & Overall & Quarter leve \\
\hline \multicolumn{5}{|l|}{ QPCR } \\
\hline Sensitivity, \% & 99.4 & $92.9-100$ & 99.4 & $92.2-100$ \\
\hline Specificity, \% & 97.1 & $78.6-100$ & 97.1 & $78.6-100$ \\
\hline \multicolumn{5}{|l|}{ APCM } \\
\hline Sensitivity, \% & 91.6 & $71.4-100$ & 79.9 & $21.4-100$ \\
\hline Specificity, \% & 100 & 100 & 100 & 100 \\
\hline
\end{tabular}




\section{QUARTER 11: QPCR and APCM}

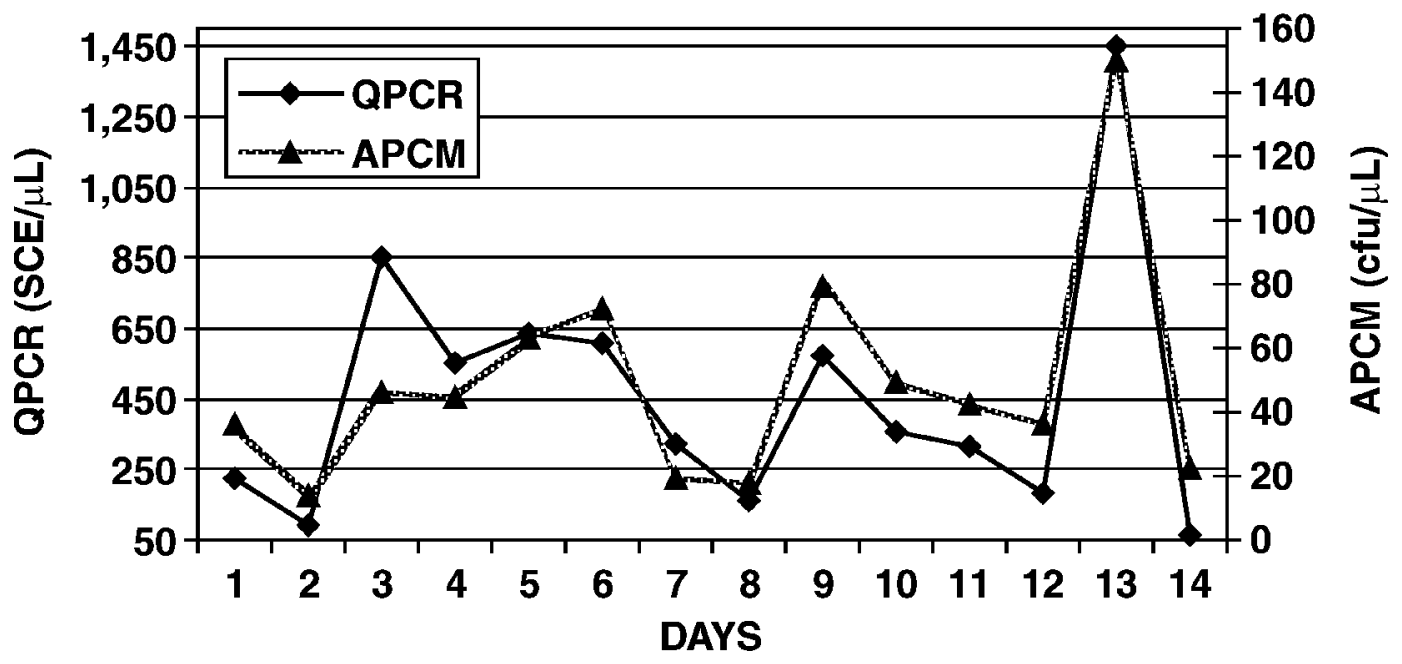

Figure 1. Shedding of Staphylococcus aureus observed in quarter 11 comparing real-time quantitative PCR (QPCR) and agar plate count method (APCM) over a sampling period of $14 \mathrm{~d}$. Results from QPCR are expressed in staphylococcal cell equivalents (SCE) per $\mu \mathrm{L}$.

during the observed period (Figure 3; 2 quarters), and a pattern without any trend (3 quarters).

Concerning the quarters with a cyclic pattern, there was a shedding minimum for all the included quarters at about $\mathrm{d} 2$ and 8 and a maximum at d 4 to 6 , resembling a sinusoidal curve (see Figure 5). To fit the data into a corresponding model, data were transformed, pooled, and synchronized as described in the Statistical Analysis section. Only the positive half-phase was mod- eled, because only part of the quarters showed a complete phase during the sampling period.

Modeling resulted in the following formula: SCE = $2.084-0.381 \times \sin (0.965 \times \mathrm{d}) ; P<0.001$ for coefficients and constant.

In addition, calculations resulted in a half-phase of $6.5 \mathrm{~d}$. Back-transformation of the data revealed that the fitted maximal SCE value (average value) was 4.8 times higher than the minimal value. Temporal depen-

\section{QUARTER 10: QPCR and APCM}

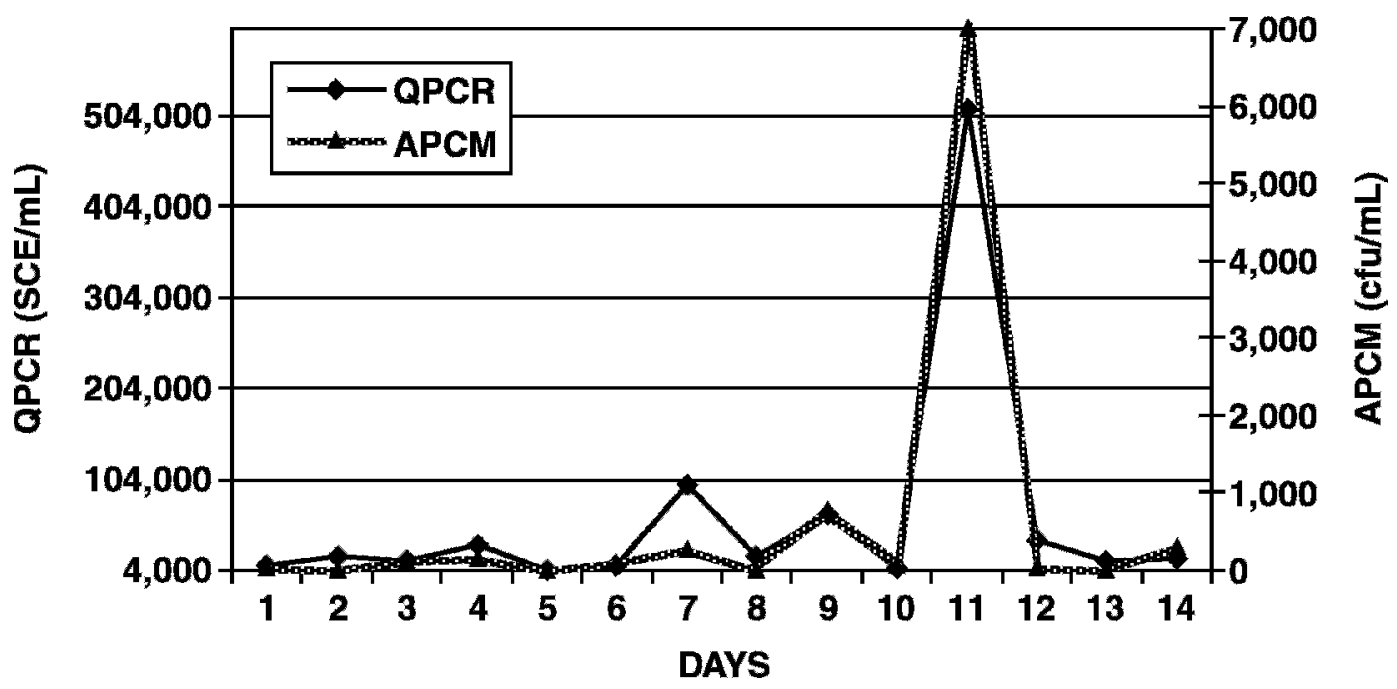

Figure 2. Shedding of Staphylococcus aureus observed in quarter 10 comparing real-time quantitative PCR (QPCR) and agar plate count method (APCM) over a sampling period of $14 \mathrm{~d}$. Results from QPCR are expressed in staphylococcal cell equivalents (SCE) per mL. On d 8,13 , and 14, quarter 10 additionally shed Corynebacterium spp. (+ or ++, semiquantitatively). 


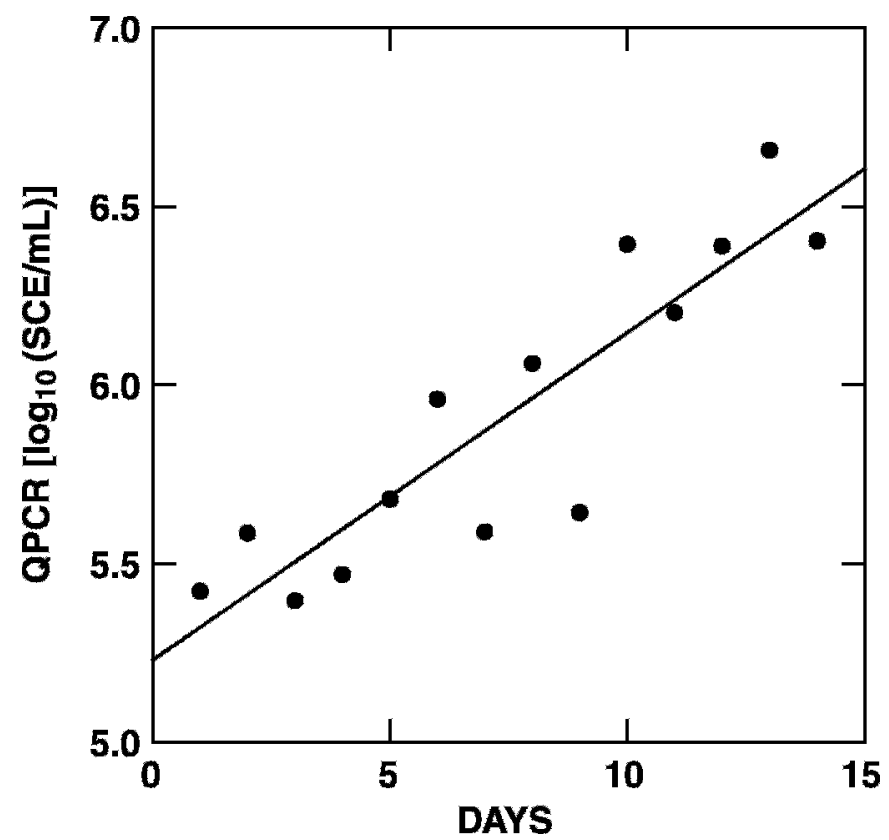

Figure 3. Shedding of Staphylococcus aureus observed in quarter 15 (representative of the quarters shedding exponentially increasing amounts of the pathogen during the 14 sampling days) measured by real-time quantitative PCR (QPCR). The data are expressed as $\log _{10^{-}}$ $\mathrm{SCE} / \mathrm{mL}$ (SCE = staphylococcal cell equivalents). The corresponding formula is $\log _{10}(\mathrm{SCE} / \mathrm{mL})=5.23+0.0917 \times$ day; $\mathrm{R}=0.891(P<0.001)$.

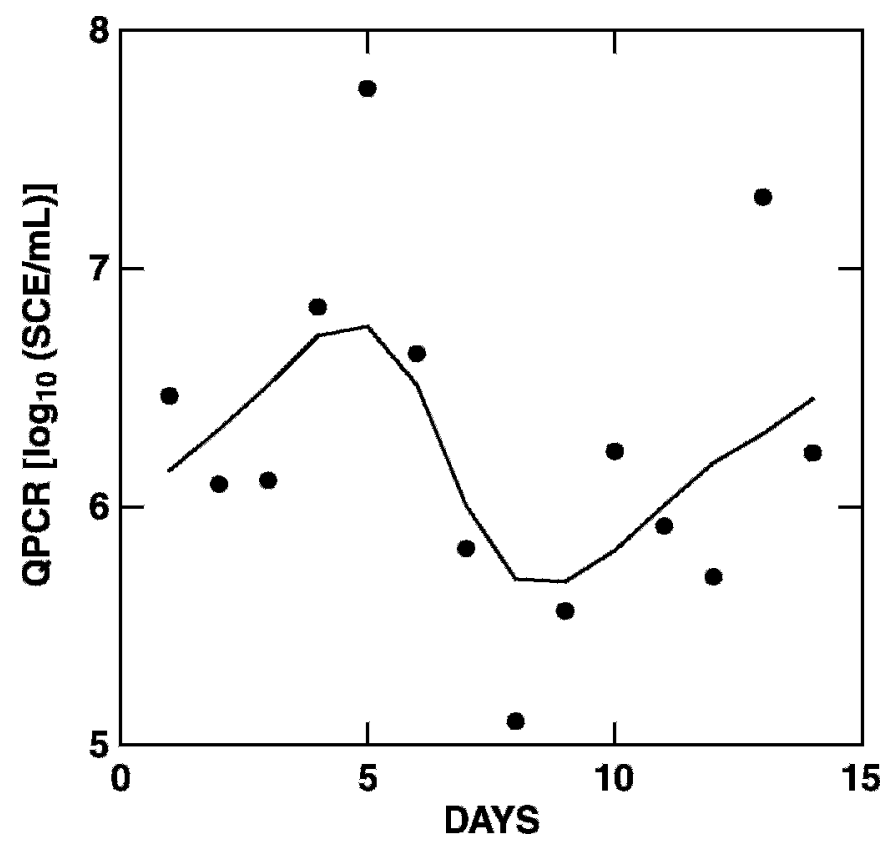

Figure 4. Shedding of Staphylococcus aureus observed in quarter 5. Measurement was done by real-time quantitative PCR (QPCR). The data are expressed as $\log _{10}-\mathrm{SCE} / \mathrm{mL}$ (SCE = staphylococcal cell equivalents) and were fitted with locally weighted regression analysis according to Cleveland (1979); note the sinusoidal course of the curve. dency of Staph. aureus shedding could be further confirmed by ANOVA $(P=0.0015)$. There was a minimum at $\mathrm{d} 2$ and $\mathrm{d} 8$ and a maximum between $\mathrm{d} 4$ and 6 , corresponding well to the sinusoidal model. The shedding curves obtained by QPCR and APCM were correlated over time (see Figures 1 and 2). Rarely (0 to 2 times per quarter), the corresponding QPCR and APCM peaks differed with a maximal difference of $1 \mathrm{~d}$. The visual impression of synchrony between the 2 analytical methods was further confirmed by statistical analysis. There was a highly significant overall synchrony $(P<$ 0.001 ) between the curves obtained by QPCR and APCM.

Figure 1 depicts the shedding pattern of quarter 11 . Staphylococcus aureus was detected by APCM on every sampling day and the number of bacteria varied between $1.40 \times 10^{4} \mathrm{cfu} / \mathrm{mL}$ and $1.50 \times 10^{5} \mathrm{cfu} / \mathrm{mL}$. The QPCR was positive on every day, varying between 6.20 $\times 10^{4} \mathrm{SCE} / \mathrm{mL}$ and $1.45 \times 10^{6} \mathrm{SCE} / \mathrm{mL}$. This shedding pattern had 3 major peaks, one of which was very obvious; the other 2 are less prominent. The synchronous course of curves is obvious in this example. Routine bacteriology using $10 \mu \mathrm{L}$ of milk would have been able to detect Staph. aureus in this quarter on every day of the sampling period.

Quarter 10 (Figure 2) shed low amounts of Staph. aureus, and APCM diagnosis was negative on $4 \mathrm{~d}$. The maximum count was $7,000 \mathrm{cfu} / \mathrm{mL}$ on $\mathrm{d} 11$. On this day, there was an obvious peak both in APCM and QPCR. In contrast to APCM, QPCR detected Staph. aureus on every day; the corresponding values varied between $4,644 \mathrm{SCE} / \mathrm{mL}$ and $5.10 \times 10^{5} \mathrm{SCE} / \mathrm{mL}$. If this quarter had undergone a routine diagnostic test (using $10 \mu \mathrm{L}$ of milk), Staph. aureus would have been successfully detected only on 3 out of $14 \mathrm{~d}$.

During the period of sampling, quarter 15 (Figure 3) shed exponentially increasing amounts of Staph. aureus starting from $700 \mathrm{cfu} / \mathrm{mL}$ or $2.18 \times 10^{5} \mathrm{SCE} / \mathrm{mL}$ on $\mathrm{d} 1$ of the sampling period to $2 \times 10^{6} \mathrm{cfu} / \mathrm{mL}$ or $4.31 \times 10^{7} \mathrm{SCE} / \mathrm{mL}$ at $\mathrm{d} 14 . \log _{10}$ transformation of the QPCR values of this particular quarter and linear regression analysis revealed the following equation:

$$
\log _{10}(\mathrm{SCE} / \mathrm{mL})=5.23+0.0917 \times \mathrm{d} .
$$

The coefficient of correlation was $R=0.891(P<0.001)$.

\section{$\operatorname{scC}$}

From the 21 analyzed quarters, we collected a total of 294 milk samples for SCC analysis. In 15 samples from infected quarters, counts of somatic cells were not possible due to clots in the milk samples. 


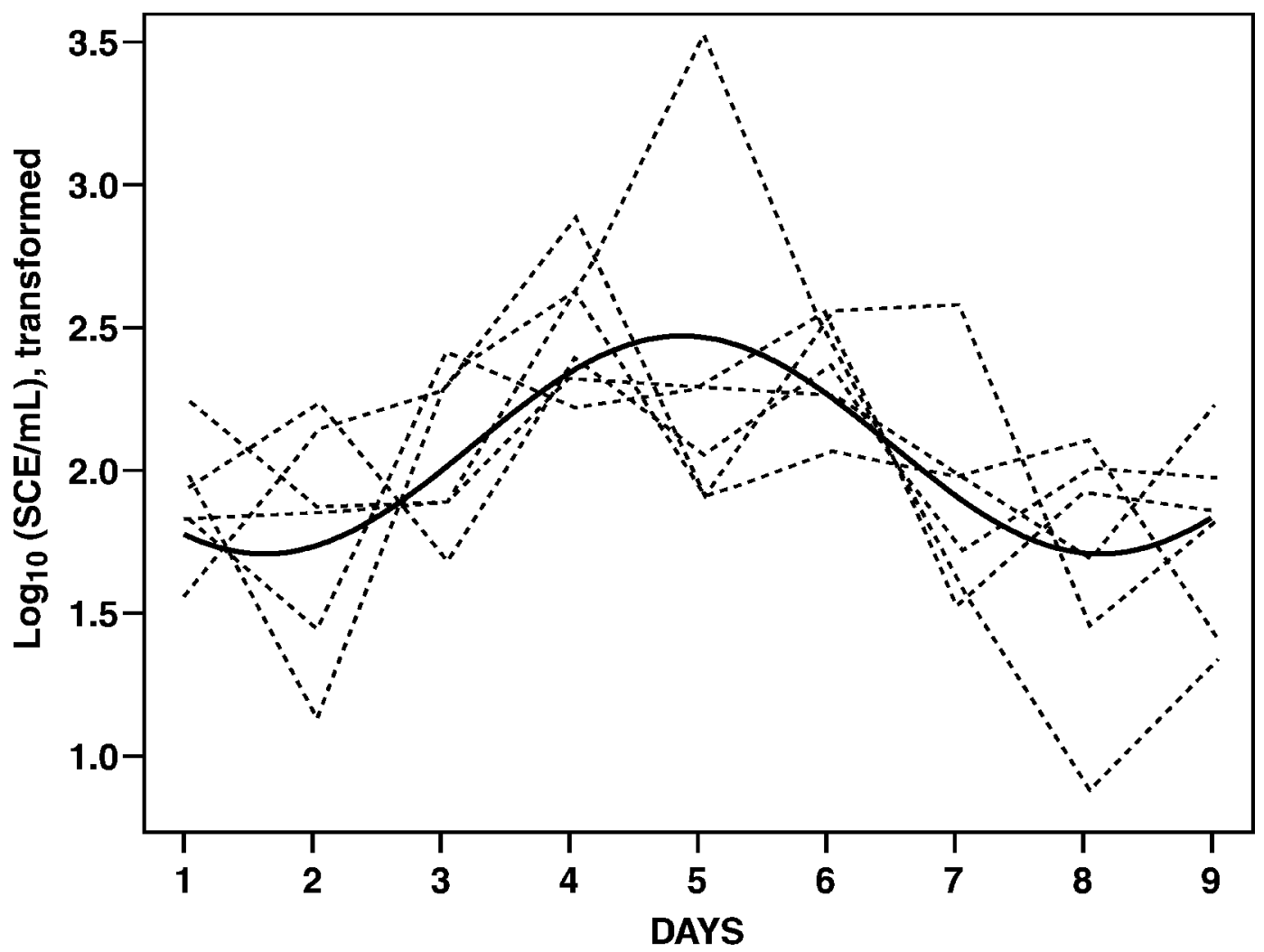

Figure 5. Cyclic shedding of Staphylococcus aureus in milk quantified by real-time quantitative PCR (QPCR). The obtained data were initially expressed as $\log _{10}-\mathrm{SCE} / \mathrm{mL}$ (SCE = staphylococcal cell equivalents). To fit a sine model, however, each value of a particular quarter was further transformed by subtracting the quarter mean and by adding a value of 2 to get positive values (log $10^{-} \mathrm{SCE} / \mathrm{mL}$, transformed). The individual phases were adjusted to achieve a common starting point for all the included quarters. The model was then fitted using a nonlinear mixed model approach assuming a sinusoidal dependency over time. Modeling was restricted to the positive half phase. According to these calculations, a half-phase duration of $6.5 \mathrm{~d}$ was obtained; the average shedding maximum was 4.8 times higher than the shedding minimum (after back transformation).

Geometric mean of SCC for the 14 sampling days in quarters with Staph. aureus IMI varied between 3.32 $\times 10^{5}$ cells $/ \mathrm{mL}$ and $6.80 \times 10^{6}$ cells $/ \mathrm{mL}$ at the quarter level, showing that there was mastitis in each case. Minimal SCC in an infected quarter was $3.60 \times 10^{4}$ cells $/ \mathrm{mL}$, and the maximal SCC was $9.05 \times 10^{6}$ cell $/ \mathrm{mL}$.

Geometric mean of SCC in individual control quarters varied between $1.10 \times 10^{4}$ cells $/ \mathrm{mL}$ and $4.30 \times 10^{4}$ cells/mL. Minimal SCC in a control quarter was 2,000 cell $\mathrm{s} / \mathrm{mL}$, and maximal SCC was $3.31 \times 10^{5}$ cell $\mathrm{s} / \mathrm{mL}$. The geometric means of quarters infected with Staph. aureus and the control quarters differed significantly $(P<0.001)$.

\section{DISCUSSION}

The purpose of this study was 1) to evaluate the diagnostic properties of the novel detection assay for Staph. aureus IMI developed by Graber et al. (2007) and 2) to investigate the shedding pattern of Staph. aureus during the 14 sampling days.
For this reason, we carried out a field study and collected and analyzed 154 milk samples from 11 quarters with natural Staph. aureus IMI. In addition, 140 samples from 10 control quarters free of Staph. aureus were processed. The test based on QPCR showed greater overall diagnostic sensitivity than APCM, especially when compared with routine bacteriology (99.4 vs. $79.9 \%$ for single samples). At the quarter level, the diagnostic sensitivity for QPCR varied between 92.9 (1 quarter) and 100\% (10 quarters) compared with 21.4 (1 quarter) and $100 \%$ (5 quarters) for routine bacteriology. Because of these excellent properties, the QPCR assay allows a simplified sampling strategy because 1 sample per quarter would be sufficient to obtain a definitive result. We are convinced that the assay will be an important and reliable tool in the future to evaluate the herd status of IMI by Staph. aureus with reasonable investment of time and money. Further studies, however, will be necessary to test the QPCR assay for the diagnostic work-up of herds. 
A further advantage of the QPCR method is its efficiency in detecting problematic quarters as can be shown in Figure 2. In this case, characterized by an APCM sensitivity of $21.4 \%$, QPCR always gave a positive result, but APCM would have been positive in only 3 out of 14 samples. Consistent detection of low-shedding quarters, however, is very beneficial because these quarters are frequently undetected by APCM and may, therefore, be long-lasting sources of infection for other quarters. Three-fold sampling can increase the sensitivity of standard bacteriology (Sears et al., 1990), but the additional costs and time required are excessive from a clinical point of view.

Additional positive properties of the assay are the simplified quantification of Staph. aureus in milk and reduction in time for analysis: about $5 \mathrm{~h}$ for QPCR vs. $48 \mathrm{~h}$ for APCM. Moreover, automation is possible for most steps of the assay so that a high sample throughput would be feasible.

The analytical sensitivity of QPCR is more than 500 times higher than standard bacteriology (Graber et al., 2007 ) and the resulting diagnostic specificity of $97.1 \%$ is also high. The false-positive results could be caused by inadequate milk collection or sample handling due to contamination or by Staph. aureus that colonize the teat skin of cow (Matos et al., 1991) or the skin of people (Jochim, 2005). Bacteriology of the positive control sample revealed additional bacteria (including CNS). From these data it is not evident whether the positive QPCR result for Staph. aureus was due to transient infection or to contamination.

The shedding curves obtained by QPCR and APCM showed a clear synchrony. There is, however, a clear quantitative difference between the methods, as can be seen in Figures 1 and 2. This difference could further be validated by regression analysis using the corresponding $\log _{10}$ SCE and $\log _{10}$ cfu values. The computation resulted in a constant value of -2.289 . Back-transformation produced a value of $194.5\left(10^{2.289}\right)$. This means that the QPCR values are, on average, about 200 times higher than those of APCM. In APCM, only bacteria with the ability to grow on agar plates can be cultured and thus quantified, whereas QPCR also detects nongrowing bacteria. Because of these factors, we conclude that the fraction of dead or nongrowing bacteria that can be measured with QPCR is considerable in milk of quarters with IMI by Staph. aureus. This finding is consistent with our earlier results (Graber et al., 2007).

During the sampling period of $14 \mathrm{~d}, 3$ shedding patterns of Staph. aureus could be observed: 1) sinusoidal cyclic activity (6 quarters); 2) log-linearly increasing shedding (2 quarters); or 3) shedding without any definite pattern (3 quarters). The cyclic pattern corresponds to the observations of Daley et al. (1991). These authors found a cyclic nature that was unique for each quarter and was not cow specific. We collated data from 6 quarters (subgroup) and used log-transformation to reduce the variation due to some extreme values. Under these conditions, we observed a half-phase duration of about $6.5 \mathrm{~d}$ and fitted a maximal SCE value (average value) that was 4.8 times higher than the minimal value. From a diagnostic point of view, the observed patterns have no consequences if detection of Staph. aureus is done by QPCR because the analytic sensitivity of the method in clinical milk samples is very high and even very small numbers of bacteria present in milk are detected. In contrast, the diagnostic sensitivity of classical bacteriology could be considerably improved if the shedding status were known. Unfortunately, this is practically never the case.

The sinusoidal shedding pattern could be caused by a synchronized process between the pathogen and the immune system: first, the shedding of Staph. aureus progresses over about $6.5 \mathrm{~d}$ and the immune system develops a response to the pathogen. Later, there is a decrease of the same duration, representing the effort of eliminating the pathogen by the immune system. This process, however, is not entirely successful and elimination of Staph. aureus is incomplete. Possibly, Staph. aureus escapes the immune system actively by invading and parasitizing the mammary epithelial cells (Almeida et al., 1996). Or it may harm the immune system by its various virulence factors which cause, among other injuries, cell lysis or induction of apoptosis (Sladek et al., 2005; Barrio et al., 2006).

Besides this cyclic pattern, suggesting synchronized interaction between the pathogen and the immune defense, 2 quarters shed log-linearly increasing amounts of bacteria, both starting at a high level $\left(2.18 \times 10^{5}\right.$ $\mathrm{SCE} / \mathrm{mL}$ and $2.64 \times 10^{5} \mathrm{SCE} / \mathrm{mL}$ ). One of these quarters showed clinical signs of progressive inflammation toward the end of the sampling period, indicating that, perhaps, the immune system was unable to control the pathogen in this case.

\section{CONCLUSIONS}

A longitudinal field study was done to evaluate the diagnostic properties of a novel QPCR-based assay to detect Staph. aureus in milk, using chronically infected quarters. The test is characterized by very high diagnostic sensitivity and specificity, which allows single milk sampling. This is in contrast to conventional bacteriological milk testing, which requires triple sampling to achieve the same diagnostic reliability. Furthermore, we demonstrated that the assay is well suited to analyze milk samples obtained under field conditions. In our 
study, the shedding pattern of Staph. aureus was cyclic (majority of cases), log-linearly increasing, or not definable. The cyclic pattern followed a sinusoidal curve.

\section{ACKNOWLEDGMENTS}

We thank D. Dietrich, Institute of Mathematical Statistics and Actuarial Science, University of Berne, Switzerland, for the support and critical review of the statistical results, and the farmers who generously allowed us to search for infected cows in their herds. This study was supported by grants of the Clinic for Ruminants and the Department of Clinical Veterinary Medicine, Vetsuisse-Faculty of Berne, Switzerland.

\section{REFERENCES}

Almeida, R. A., K. R. Matthews, E. Cifrian, A. J. Guidry, and S. P. Oliver. 1996. Staphylococcus aureus invasion of bovine mammary epithelial cells. J. Dairy Sci. 79:1021-1026.

Barrio, M. B., P. Rainard, and G. Prevost. 2006. LukM/LukF'-PV is the most active Staphylococcus aureus leukotoxin on bovine neutrophils. Microbes Infect. 8:2068-2074.

Buelow, K. L., C. B. Thomas, W. J. Goodger, K. V. Nordlund, and M. T. Collins. 1996. Effect of milk sample collection strategy on the sensitivity and specificity of bacteriologic culture and somatic cell count for detection of Staphylococcus aureus intramammary infection in dairy cattle. Prev. Vet. Med. 26:1-8.

Cleveland, W. S. 1979. Robust locally weighted regression and smoothing scatterplots. J. Am. Stat. Assoc. 74:829-836.

Daley, M. J., E. R. Oldham, T. J. Williams, and P. A. Coyle. 1991. Quantitative and qualitative properties of host polymorphonuclear cells during experimentally induced Staphylococcus aureus mastitis in cows. Am. J. Vet. Res. 52:474-479.

Godden, S. M., J. T. Jansen, K. E. Leslie, N. L. Smart, and D. F. Kelton. 2002. The effect of sampling time and sample handling on the detection of Staphylococcus aureus in milk from quarters with subclinical mastitis. Can. Vet. J. 43:38-42.

Graber, H. U., M. G. Casey, J. Naskova, A. Steiner, and W. Schaeren. 2007. Development of a highly sensitive and specific assay to detect Staphylococcus aureus in bovine mastitic milk. J. Dairy Sci. 90:4661-4669.

Jochim, M. 2005. Genotypic comparison of Staphylococcus aureus variants from human nasal carriers and bovine chronic mastitis. Doctoral Thesis. Vetsuisse-Faculty, University of Berne, Switzerland.
Kirchhofer, M., L. Tavel, D. Strabel, C. Fournier, A. Steiner, H. U. Graber, and T. Kaufmann. 2007. Herd problem: Udder health. Retrospective study of farms with udder health problems assessed by the Swiss Bovine Health Service (BHS) from 1999 to 2004. DTW Dtsch. Tierärztl. Wochenschr. 117:338-344.

Matos, J. S., D. G. White, R. J. Harmon, and B. E. Langlois. 1991. Isolation of Staphylococcus aureus from sites other than the lactating mammary gland. J. Dairy Sci. 74:1544-1549.

National Mastitis Council (NMC). 1999. Laboratory Handbook on Bovine Mastitis. Rev. ed. National Mastitis Council Inc., Madison, WI.

Neijenhuis, F., H. W. Barkema, H. Hogeveen, and J. P. Noordhuizen. 2000. Classification and longitudinal examination of callused teat ends in dairy cows. J. Dairy Sci. 83:2795-2804.

OIE. 2004. Manual of diagnostic tests and vaccines for terrestrial animals. 5th ed. OIE World Organisation for Animal Health, Paris, France.

Radostits, O. M., C. G. Gay, D. C. Blood, and K. W. Hinchcliff. 2000 Veterinary Medicine. A Textbook of the Diseases of Cattle, Sheep, Pigs, Goats and Horses. 9th ed. W.B. Saunders, Philadelphia, PA.

Schukken, Y. H., D. J. Wilson, F. Welcome, L. Garrison-Tikofsky, and R. N. Gonzalez. 2003. Monitoring udder health and milk quality using somatic cell counts. Vet. Res. 34:579-596.

Sears, P. M., B. S. Smith, P. B. English, P. S. Herer, and R. N. Gonzalez. 1990. Shedding pattern of Staphylococcus aureus from bovine intramammary infections. J. Dairy Sci. 73:2785-2789.

Sears, P. M., D. J. Wilson, R. N. Gonzalez, and D. D. Hancock. 1991. Microbiological results from milk samples obtained premilking and postmilking for the diagnosis of bovine intramammary infections. J. Dairy Sci. 74:4183-4188.

Seegers, H., C. Fourichon, and F. Beaudeau. 2003. Production effects related to mastitis and mastitis economics in dairy cattle herds. Vet. Res. 34:475-491.

Sieber, R. L., and R. J. Farnsworth. 1984. Differential diagnosis of bovine teat lesions. Vet. Clin. North Am. Large Anim. Pract. 6:313-321.

Sladek, Z., D. Rysanek, H. Ryznarova, and M. Faldyna. 2005. Neutrophil apoptosis during experimentally induced Staphylococcus aureus mastitis. Vet. Res. 36:629-643.

Wesson, C. A., L. E. Liou, K. M. Todd, G. A. Bohach, W. R. Trumble, and K. W. Bayles. 1998. Staphylococcus aureus Agric. and Sar global regulators influence internalization and induction of apoptosis. Infect. Immun. 66:5238-5243.

Zadoks, R. N., H. G. Allore, H. W. Barkema, O. C. Sampimon, G. J. Wellenberg, Y. T. Grohn, and Y. H. Schukken. 2001. Cow- and quarter-level risk factors for Streptococcus uberis and Staphylococcus aureus mastitis. J. Dairy Sci. 84:2649-2663.

Zecconi, A., R. Piccinini, A. Zepponi, and G. Ruffo. 1997. Recovery of Staphylococcus aureus from centrifuged quarter milk samples. J. Dairy Sci. 80:3058-3063. 